\title{
ENSINO FUNDAMENTAL DE NOVE ANOS: UM NOVO CAMINHO EM VELHA ESTRADA? UM VELHO CAMINHO EM NOVA ESTRADA?
}

\author{
ELEMENTARY SCHOOL IN NINE YEAR: A NEW WAY IN A OLD ROAD? \\ AN OLD WAY IN A NEW ROAD?
}

\section{LA ENSEÑANZA FUNDAMENTAL DE NUEVE AÑOS: ¿UN NUEVO CAMINO EN UNA VIEJA CARRETERA? ¿UN VIEJO CAMINO EN UNA NUEVA CARRETERA?}

\author{
Cecília lacoponi Hashimoto* \\ Vera Maria Nigro de Souza Placco**
}

\begin{abstract}
Resumo: Este artigo discute alguns resultados de uma pesquisa de doutorado em Educação: Psicologia da Educação, realizada em 2011, cujo objetivo foi analisar o processo de ampliação do Ensino Fundamental para nove anos, segundo a lei 11.274/2006 e seus instrumentos decorrentes. O foco da pesquisa foi verificar como essa mudança foi vivenciada por professores e gestores desse segmento no que tange ao atendimento pedagógico da criança, à sua aprendizagem, à estrutura física das salas de aula, à discussão da própria legislação; quem são os professores que estão à frente do primeiro ano, qual é sua identidade profissional, e quais são os encaminhamentos sugeridos para o trabalho com esse primeiro ano. Este trabalho ocorreu em um município que dista 100 km da cidade de São Paulo, em uma escola particular e em quatro escolas municipais, com quatro professores e três gestores. Os achados da pesquisa revelaram que a implantação do Ensino Fundamental de nove anos ocorreu de maneira aligeirada, não dando prioridade à formação e à participação efetiva dos professores e gestores nas discussões prévias e tampouco nas tomadas de decisões, gerando desconhecimento e insegurança do professorado quanto à proposta de ampliação do ensino obrigatório. Os espaços escolares continuam inadequados para receber a criança de 6 anos. A prática pedagógica tem sido organizada sem o conhecimento das orientações do MEC e de um referencial teórico que balize o desenvolvimento infantil nessa faixa etária - e também sem orientações e reflexões sobre quais conteúdos devem ser trabalhados no primeiro ano do Ensino Fundamental. Nossa pesquisa revela um impasse, uma indefinição em relação à constituição identitária do professor que deve assumir esse primeiro ano.
\end{abstract}

Palavras-chave: Ensino fundamental de nove anos. Reformas do Ensino. Transição entre Educação Infantil e Ensino Fundamental. Professores. Identidade.

Abstract: This article discusses some results of a research for a doctorate thesis in Education: Educational Psychology, held in 2011, which aimed at analyzing the process of expanding Elementary School to nine years, according to Law no. 11.274/2006 and its derived instruments. The research focused on determining how this change was experienced by teachers and managers of this segment regarding the

\footnotetext{
* Doutora em Educação: Psicologia da Educação pela PUC-SP. Consultora e palestrante pela Lebre Consulting Ltda, na qual é sócio-diretora. Psicopedagoga Clínica no Centro de Atendimento Integrado Fonoaudiológico e Psicopedagógico em Itu/SP. Correio eletrônico: <ceciliaiacoponi@uol.com.br>.

** Doutora em Educação: Psicologia da Educação pela PUC-SP. Professora do Programa de Pós-Graduação em Educação: Psicologia da Educação da PUC-SP. E-mail: <veraplacco@pucsp.br>.
} 
pedagogic approach of the child, their learning, the physical structure of classrooms, the discussion of the legislation itself; who are the teachers responsible for the first grade, which is their professional identity, and what are the suggested directions to work with students of the first grade. This research took place in a city that is 100 kilometers away from the city of São Paulo, in one private school and four public schools, with four teachers and three managers. The results revealed that the implementation of a nine-year Elementary School was so watered down, not giving priority to training and the effective participation of teachers and managers in previous discussions, nor in decision-making, that generated insecurity and lack of knowledge among teachers regarding the proposal of extension of compulsory education. School spaces remained inadequate for 6-years-old children. Teaching practice is organized without taking into consideration MEC's guidelines and a theoretical framework which limits child development at this age - and also without guidance and reflections on what content should be worked in the first grade of Elementary School. Our research reveals a deadlock, a blurring regarding the identity constitution of the teacher responsible for the first grade.

Keywords: Nine-year Elementary School. School reform. Transition between Early Childhood Education and Elementary School. Teachers. Identity.

Resumen: Este artículo discute algunos resultados de una investigación de doctorado en Educación (Psicología de la Educación), realizada en 2011, cuyo objetivo fue analizar el proceso de ampliación de la Enseñanza primaria para nueve años, según la ley 11.274/2006 y sus instrumentos derivados. El foco de la investigación fue la averiguación de cómo este cambio lo vivieron los profesores y gestores de este segmento en lo que se refiere a la atención pedagógica del niño, a su aprendizaje, a la estructura física de las salas de aula, a la discusión de la propia legislación; quiénes son los profesores que están al frente del primer año, cuál es su identidad profesional, y cuáles son las directrices sugeridas para el trabajo con ese primer año. Este trabajo se llevó a cabo en un municipio ubicado a $100 \mathrm{~km}$ de la ciudad de São Paulo, en una escuela privada y en cuatro escuelas municipales, con cuatro profesores y tres gestores. Los hallazgos de la investigación revelaron que la implantación de la Enseñanza primaria de nueve años ocurrió de manera aligerada, sin que se priorizara la formación y la participación efectiva de los profesores y gestores en las discusiones previas y tampoco en las tomadas de decisiones, lo que generó desconocimiento y inseguridad del profesorado en cuanto a la propuesta de ampliación de la enseñanza obligatoria. Los espacios escolares permanecen inadecuados para recibir a niños de 6 años. La práctica pedagógica se ha organizado sin el conocimiento de las orientaciones del MEC y de un referencial teórico que oriente el desarrollo infantil en este grupo etario, y además sin orientaciones y reflexiones sobre cuáles contenidos deben trabajarse en el primer año de la Enseñanza primaria. Nuestra investigación revela un punto crítico, una indefinición en cuanto a la constitución de la identidad del profesor que debe hacerse cargo de este primer año.

Palabras clave: Enseñanza fundamental de nueve años. Reformas de la Enseñanza. Transición entre la Educación Infantil y la Enseñanza primaria. Profesores. Identidad.

\section{Introdução}

Com a promulgação da Lei $n^{\circ}$. 11.274/2006, que amplia o Ensino Fundamental para nove anos, um novo lugar é definido para a criança de 6 anos, que, até então, fazia parte do último ano da Educação Infantil, situando-a no primeiro ano do segmento seguinte. Essa mudança desencadeou várias necessidades, oriundas de uma nova configuração que ora se estabelece para o ensino no país, as quais buscamos investigar neste trabalho. 
Assim, questionamos a maneira como essa ampliação do segmento fundamental se concretizou nas escolas, considerando se professores e gestores tiveram formação e conhecimento com vistas aos documentos formais disponibilizados pelo MEC. Também buscamos saber em que medida os professores estavam preparados para assumir essas crianças de 6 anos no Ensino Fundamental. Investigamos como foi a passagem dessas crianças do Infantil para o ciclo seguinte e sua recepção por parte do Ensino Fundamental, e se houve efetivamente um trabalho de preparo para tal recepção (organização curricular, metodológica e de conteúdos; organização de espaços próprios, incluindo salas de aula, mobiliário, área externa e demais estruturas que compõem a educação de crianças de 6 anos). Discutimos, também, quem é o professor que no município pesquisado está à frente do trabalho com as crianças do primeiro ano do Ensino Fundamental.

O foco no professor que está à frente do primeiro ano de Ensino Fundamental nesse município (situado a $100 \mathrm{~km}$ da cidade de São Paulo) foi uma tentativa de elucidar qual seria a identidade do profissional que abraça o primeiro ano desse segmento. Tivemos acesso a uma escola particular e a quatro municipais, tendo como participantes uma professora e uma gestora da escola particular e três professoras e duas gestoras da municipal. Vale dizer que os achados são significativos para esse município, com esses sujeitos.

Assim, tendo em vista esse novo quadro que se instala no cenário escolar brasileiro, documentos, pareceres, resoluções e normas despontaram nesse universo, com o objetivo de instrumentalizar supervisores, gestores e professores nas novas propostas que emergiram para o Ensino Fundamental de nove anos.

Trata-se de um assunto que apresenta opiniões que vão desde a aceitação e defesa da mudança, com vistas à ampliação da escolaridade para a criança de 6 anos, até a recusa, pautada em conceitos que preferem a criança de 6 anos ainda na Educação Infantil, com planos curriculares ancorados no brincar, na ludicidade, nos espaços específicos para o desenvolvimento dessa criança. Diante desse cenário, alguns estudos começaram a proliferar no país a partir de 2006, também com o objetivo discutir a implantação do Ensino Fundamental de nove anos.

Dentre esses estudos, interessaram-nos as contribuições de Arelaro, Jacomini e Klein (2011); Correa (2011); Kishimoto, Pinazza, Morgado e Toyofuki (2011); Nogueira e Catanante (2011) e Pansini e Marin (2011), que inicialmente buscaram o amparo legal das normas de implantação do Ensino Fundamental de nove anos para posteriormente subsidiar a pesquisa. Utilizaram entrevistas com professores e gestores, no intuito de averiguar a mudança e seus entraves. Esses trabalhos se desenvolveram em pontos isolados e distantes, na grande São Paulo, no interior de São Paulo e em outros Estados, o que, ao final das leituras, traz rico material de análise relativa à mudança para o país.

Salvo a experiência de Kishimoto, Pinazza, Morgado e Toyofuki (2011), que já em 2006 consideraram uma reestruturação curricular para a criança de 6 anos mediante as novas orientações legais de implantação do Ensino Fundamental de nove anos, as demais pesquisas trazem um universo de desconhecimento - tanto dos documentos legais quanto das propostas de implantação. Denunciam a falta de formação do profissional (professores e gestores) para tal mudança, bem como o aligeiramento na condução dos trabalhos que deveriam ser realizados, o que gerou insatisfação e dúvidas.

Esta pesquisa considerou que as mudanças do sistema de ensino, instituídas por 
normas legais, têm significado e resultados na medida em que, por um lado, são decorrência de necessidades identificadas nesse sistema, e, por outro, resultam de amplas discussões e reflexões dos educadores a respeito. Caso isso não ocorra, haverá dificuldades para sua implantação.

Interessou-nos, além do que já havia na literatura vigente, fazer um apanhado geral dos instrumentos decorrentes da lei $11.274 / 2006$, os quais nos subsidiaram em nossos questionamentos.

Para realizar este trabalho, após a definição do problema e a verificação dos trabalhos acima citados, consultamos o histórico da legislação de ensino no país e os autores que tratavam da temática "reforma" (Ferreira, 2008; Evangelista e Shiroma, 2007; Almeida, 2006; Cunha, 1999; Lourencetti , 2006; Imbernón, 2006), visto que havia necessidade de ser garantir um cabedal teórico que assegurasse a análise dos dados. Delimitamos os sujeitos da pesquisa - professores do primeiro ano do Ensino Fundamental de escolas municipais e particulares e também gestores do Ensino Fundamental -, considerando que estes não só fazem parte do processo de implantação da nova medida legal como também são os responsáveis pela transição junto aos professores. Apresentamos, a seguir, a caracterização dos sujeitos participantes da pesquisa (nas Tabelas 1 e 2).

Utilizamos questionários que revelassem o perfil dos entrevistados e entrevistas semiestruturadas, com questões que contemplassem os direcionamentos e encaminhamentos prescritos pela lei e seus instrumentos decorrentes. Também nos valemos da observação casual dos ambientes em que a pesquisa foi realizada.

Mediante a análise dos dados coletados, procurou-se compreender se as propostas da Lei $\mathrm{n}^{\circ} 11.274 / 2006$ e dos pareceres decorrentes foram alcançadas. No decorrer da análise dos dados, alguns autores, em especial, são convidados a discutir temáticas recorrentes nas falas dos entrevistados. Assim temos, dentre outros, Dubar (2005) - Identidade; Nóvoa (2009) - Inovação; Shulman (1987) Conhecimento do ensino; Tardif (2012) Saberes da Experiência.

\section{O Ensino Fundamental e a legislação}

O ensino hoje conhecido como fundamental passou por mudanças significativas ao longo de seu percurso. Frequentemente, em seus objetivos e no nível de ensino, esteve em pauta uma organização escolar que ora atendesse à formação de um indivíduo para ingresso rápido no mundo do trabalho, ora à formação geral, elitista, voltada para o caminho da universidade.

No Brasil, as mudanças ocorridas na Educação, em sua maioria, buscaram atender ao fator demanda, ou seja, à necessidade de capacitar pessoas para determinadas funções, situadas historicamente, e que, por intermédio da escola, conseguissem, em breve período de tempo, conquistar os conhecimentos básicos inerentes a tais responsabilidades.

Dessa forma, a partir de 1930, sofremos várias modificações na maneira de organizar a educação no país, até chegar àquela que seria a primeira grande lei brasileira da educação nacional, datada de 20 de dezembro de 1961. Nesta, a obrigatoriedade do ensino para crianças era de quatro anos, ou seja, a criança que terminasse o Ensino Primário, aos 11 anos, já teria um diploma. Isso porque ela deveria ter um mínimo de escolarização que lhe garantisse leitura, escrita e pequenos cálculos e que a auxiliasse no futuro mundo do trabalho. 
Tabela 1. Caracterização dos professores participantes do $1^{\circ}$ ano do Ensino Fundamental: dados até março de 2011 (As siglas das escolas representam respectivamente: EPC - Escola Particular C; EMP - Escola Municipal P; EMQ - Escola Municipal Q; EMR - Escola Municipal R; EMS - Escola Municipal S.)

\begin{tabular}{|c|c|c|c|c|c|c|c|c|}
\hline Professor & Escola & Idade & $\begin{array}{c}\text { Tempo de } \\
\text { trabalho } \\
\text { na área de } \\
\text { Educação }\end{array}$ & $\begin{array}{c}\text { Tempo } \\
\text { como } \\
\text { professora } \\
\text { de crianças } \\
\text { de } 6 \text { anos } \\
\text { no Ensino } \\
\text { Infantil }\end{array}$ & $\begin{array}{c}\text { Tempo como } \\
\text { professora } \\
\text { de crianças } \\
\text { de } 6 \text { anos no } \\
\text { Ensino Fun- } \\
\text { damental }\end{array}$ & $\begin{array}{l}\text { Ensino } \\
\text { Médio }\end{array}$ & $\begin{array}{l}\text { Curso } \\
\text { Superior }\end{array}$ & Pós-Graduação \\
\hline Rute & EPC & $\begin{array}{c}53 \\
\text { anos }\end{array}$ & 27 anos & 15 anos & 5 anos & $\begin{array}{l}\text { Curso de } \\
\text { Magistério }\end{array}$ & Pedagogia & Psicopedagogia \\
\hline Silvana & EMP & $\begin{array}{c}44 \\
\text { anos }\end{array}$ & 25 anos & 17 anos & 2 anos & $\begin{array}{l}\text { Curso de } \\
\text { Magistério }\end{array}$ & Pedagogia & Não tem \\
\hline Leila & EMR & $\begin{array}{c}45 \\
\text { anos }\end{array}$ & 26 anos & ------ & 2 anos & $\begin{array}{l}\text { Curso de } \\
\text { Magistério }\end{array}$ & Pedagogia & $\begin{array}{l}\text { Psicopedagogia } \\
\text { Educação Infantil } \\
\text { Letramento e } \\
\text { Alfabetização (em } \\
\text { andamento) }\end{array}$ \\
\hline Maura & EMS & $\begin{array}{c}42 \\
\text { anos }\end{array}$ & 24 anos & 10 anos & 2 anos & $\begin{array}{l}\text { Curso de } \\
\text { Magistério }\end{array}$ & Pedagogia & $\begin{array}{l}\text { Arte-Terapia } \\
\text { Gestão Escolar }\end{array}$ \\
\hline
\end{tabular}

Tabela 2. Caracterização dos gestores participantes: dados até março de 2011

\begin{tabular}{l|c|c|c|c|c|c|c}
\hline Gestor & Escola & Idade & $\begin{array}{c}\text { Tempo de } \\
\text { trabalho } \\
\text { na área de } \\
\text { Educação }\end{array}$ & $\begin{array}{c}\text { Tempo como } \\
\text { gestora do } \\
\text { Ensino Funda- } \\
\text { mental }\end{array}$ & $\begin{array}{c}\text { Ensino } \\
\text { Médio }\end{array}$ & $\begin{array}{c}\text { Curso } \\
\text { Superior }\end{array}$ & Pós-graduação \\
Clara & EPC & 30 anos & 9 anos & 9 anos & $\begin{array}{l}\text { Curso de } \\
\text { Magistério }\end{array}$ & Pedagogia & $\begin{array}{l}\text { Psicopedagogia (incom- } \\
\text { pleto) }\end{array}$ \\
\hline Débora & EMP & 43 anos & 25 anos & 3 anos & $\begin{array}{l}\text { Curso de } \\
\text { Magistério }\end{array}$ & Pedagogia & $\begin{array}{l}\text { Educacional e Gestão do } \\
\text { Trabalho (em andamento) }\end{array}$ \\
\hline Lina & EMQ & 45 anos & 27 anos & 2 anos & $\begin{array}{l}\text { Curso de } \\
\text { Magistério }\end{array}$ & Pedagogia & Psicopedagogia \\
\hline
\end{tabular}

Passados dez anos, em 1971, com a promulgação da LDB $n^{\circ} 5.692 / 71$, alterou-se substancialmente a organização da educação, que foi ordenada em períodos, séries e etapas a ser vencidas pelos discentes na configuração de graus de ensino. O que antes era considerado caráter terminal, na Lei $n^{\circ} 4.024 / 61$, no que diz respeito à idade da criança na escola - com 11 anos já saía com um diploma, ao findar o Ensino Primário -, sofre modificação, aumentando-se o tempo de obrigatoriedade na escola, de modo que o primeiro “diploma” será conferido aos 14 anos, momento em que se encerra uma etapa 
de ensino, o chamado Primeiro Grau. Assim, o Ensino Básico e Fundamental dessa época correspondia ao Primeiro Grau, com a criança ingressando na escola aos 7 anos de idade, no primeiro ano do Primeiro Grau, e terminando seus estudos aos 14 anos, no oitavo ano, completando oito anos de escolaridade contínua.

Nota-se que, ao longo dessa trajetória de Leis, Pareceres e documentos legais, a tônica sempre é a busca da garantia de uma escolaridade obrigatória, ao menos no ensino considerado fundamental. Há uma preocupação em se absorver essa fatia da população que, estando em idade escolar inicial (considerando-se crianças por volta de 6 anos), não está satisfatoriamente matriculada, mesmo havendo indicativos de que o poder público é responsável por subsidiar esse ensino e que aos pais cabe a tarefa de matricular os filhos na escola.

Ainda para garantir a questão de destaque e prioridade na educação do país, temos a Constituição da República Federativa do Brasil, de 5 de outubro de 1988, que enaltece a educação como um dos direitos sociais mais importantes, apresentando-o à frente dos demais, e o Estatuto da Criança e do Adolescente (ECA), Lei Federal n ${ }^{\circ}$ 8.069, de 13 de julho de 1990, que retrata a preocupação com o direito à educação, caracterizando a proteção da criança e do adolescente, em primeira instância, e confirmando os preceitos legais da obrigatoriedade do ensino.

Continuando a trajetória das leis, em 1996, também com inspiração na Constituição de 1988, nasce a Lei $n^{\circ}$ 9.394/96, que oficialmente reconhece a Educação Infantil como parte integrante da Educação Básica e lança objetivos para o Ensino Fundamental: “Art. 21. A educação escolar compõe-se de: I - Educação Básica, formada pela Educação Infantil, Ensino
Fundamental e Ensino Médio”. No artigo 32, lança seus objetivos ao longo dos oitos anos: "Art. 32. O Ensino Fundamental obrigatório, com duração de oito anos, obrigatório e gratuito na escola pública, terá por objetivo a formação básica do cidadão.”

A partir desta lei (LDB no 9.394/96), há orientações da matrícula de crianças de 6 anos no Ensino Fundamental, visto que tal prática já ocorria em pontos isolados do país. Em seguida, considerando-se que há uma situação de inchaço no Ensino Fundamental, decorrente da distorção série-idade, que, no primeiro ano, ora atende crianças de 6 anos, ora de 7, em 9 de janeiro de 2001 é sancionado o PNE - Plano Nacional de Educação, Lei $\mathrm{n}^{\circ} 10.172$, fixando as metas e diretrizes para os dez anos seguintes, considerando, segundo dados do Censo Escolar, que há um montante de $46 \%$ dos alunos do Ensino Fundamental com idade superior à faixa etária correspondente a cada série, chegando o índice de distorção no Nordeste a 64\%. Essa problemática retratava, para a época, a dimensão de ineficiência do sistema educacional brasileiro. Pelos dados estatísticos, os alunos levavam 10,4 anos para completar as oito séries do Ensino Fundamental.

Com vistas aos dados do PNE/ 2001, em 16 de maio de 2005, institui-se a Lei $\mathrm{n}^{\circ} 11.114$, que altera os artigos 6, 30, 32 e 87 da Lei $\mathrm{n}^{\circ} 9.394$, de 20 de dezembro de 1996, com o objetivo de tornar obrigatório o início do Ensino Fundamental aos 6 anos de idade. Na sequência, e dando continuidade ao amparo legal - de modo a reafirmar a matrícula de crianças com 6 anos no Ensino Fundamental -, em 6 de fevereiro de 2006 é sancionada a Lei $n^{\circ} 11.274 / 2006$, que altera a redação dos artigos $29,30,32$ e 87 da Lei $n^{\circ}$ 9.394, de 20 de dezembro de 1996, e estabelece "as diretrizes e bases da educação nacional, dispondo sobre a duração de 9 (nove) anos para o ensino fundamental, com 
matrícula obrigatória a partir dos 6 (seis) anos de idade", e institui-se o ano de 2010 como data limite para se concretizar a adaptação à nova regra legislativa.

Assim, o Ensino Fundamental é definido com nove anos de duração, e a Educação Infantil é reestruturada, passando a ter cinco anos de duração, o que, anteriormente, atendia aos alunos até os 6 anos de idade.

Essa decisão político-social de se buscar a ampliação do Ensino Fundamental como um ajuste à escolaridade das crianças de classes menos favorecidas também se deve ao fato de se buscar privilegiar os setores populares, já que as crianças de 6 anos das classes média e alta já frequentam o sistema de ensino, tanto na Educação Infantil quanto no Ensino Fundamental. - na pré-escola ou na primeira série do Ensino Fundamental. “A opção pela faixa etária dos 6 aos 14 e não dos 7 aos 15 anos para o Ensino Fundamental de nove anos segue a tendência das famílias e dos sistemas de ensino de inserir progressivamente as crianças de 6 anos na rede escolar" (EF9 ANOS: ORIENTAÇÕES GERAIS, MEC, 2004, p.16). Observe-se ainda que os indicadores nacionais apontam que, atualmente,

[...] das crianças em idade escolar, 3,6\% ainda não estão matriculadas. Entre aquelas que estão na escola, $21,7 \%$ estão repetindo a mesma série e apenas $51 \%$ concluirão o Ensino Fundamental, fazendo-o em 10,2 anos em média. Acrescenta-se, ainda, que em torno de 2,8 milhões de crianças de 7 a 14 anos estão trabalhando, o que, por si só, já é comprometedor, mais ainda quando cerca de 800 mil dessas crianças estão envolvidas em formas degradantes de trabalho, inclusive a prostituição infantil (EF9 ANOS: ORIENTAÇÕES GERAIS, MEC, 2004, p. 2004, p. 6).
Coube à pesquisa, portanto, verificar como foi se concretizou a mudança do Ensino Fundamental de 9 anos, no que tange à criança de 6 anos no primeiro ano.

A seguir apresentamos dois quadros, a fim de sintetizar nossos estudos.

(Nesse quadro, não consideramos para a Lei $n^{\circ} 4.024 / 61$, os ciclos Ginasial e Colegial, por corresponderem ao Ensino Secundário e Ensino Médio da época).

\section{As reformas, as políticas e seus efeitos}

O tema das reformas de ensino tem sido bastante discutido por pesquisadores, com o intuito de enfocar os desdobramentos que estas podem causar tanto para professores e gestores quanto para o entorno. Considerando as devolutivas dos questionários, um dos aspectos que inicialmente nos chamaram a atenção, antes de analisarmos a reforma que a lei 11.274/2006 trouxe para o município estudado, refere-se à carência de professor do sexo masculino nas escolas pesquisadas, no segmento Ensino Fundamental I. Todos os sujeitos que foram entrevistados são do sexo feminino. Temos em Gatti (1996) e Cunha (1999) uma análise acerca da feminização do magistério.

Gatti (1996), em sua pesquisa, objetivou investigar o professor e sua identidade, quais representações possui de si mesmo como profissional e pessoa, como essas representações são incorporadas em suas ações e na sua formação, bem como a importância da compreensão do que significa o "ser-professor", que desencadeia o "fazer-professor”. 
Quadro 1. Evolução do Ensino Fundamental brasileiro

\begin{tabular}{|c|c|c|c|c|}
\hline Leis & Lei $n^{\circ} 4024 / 61$ & Lei $n^{\circ} 5692 / 71$ & Lei $n^{\circ} 9394 / 96$ & Lei $n^{\circ} 11274 / 06$ \\
\hline Nomenclatura & Ensino Primário & Ensino de $1^{\circ}$ Grau & $\begin{array}{l}\text { Ensino Fundamen- } \\
\text { tal }\end{array}$ & Ensino Fundamental \\
\hline Objetivo & $\begin{array}{l}\text { Art. } 1^{\circ} \text { - A educação nacional, } \\
\text { inspirada nos princípios de } \\
\text { liberdade e nos ideais de } \\
\text { solidariedade humana, tem } \\
\text { por fim: } \\
\text { a) a compreensão dos direitos } \\
\text { e deveres da pessoa humana, } \\
\text { do cidadão, do Estado, da } \\
\text { família e dos demais grupos } \\
\text { que compõem a comunidade; } \\
\text { (b) o respeito à dignidade e } \\
\text { às liberdades fundamentais } \\
\text { do homem; c) o fortalecimen- } \\
\text { to da unidade nacional e da } \\
\text { solidariedade internacional; } \\
\text { (d) o desenvolvimento inte- } \\
\text { gral da personalidade humana } \\
\text { e a sua participação na obra } \\
\text { do bem comum; } \\
\text { e) o preparo do indivíduo e } \\
\text { da sociedade para o domínio } \\
\text { dos recursos científicos e } \\
\text { tecnológicos que lhes permi- } \\
\text { tam utilizar as possibilidades } \\
\text { e vencer as dificuldades do } \\
\text { meio; (Revogado pela Lei no } \\
\text { 9.394, de 1996) } \\
\text { f) a preservação e expansão. }\end{array}$ & $\begin{array}{l}\text { Art. } 17 \text { - O ensino de } \\
1^{\circ} \text { grau destina-se à } \\
\text { formação da criança } \\
\text { e do pré-adoles- } \\
\text { cente, variando em } \\
\text { conteúdo e métodos } \\
\text { segundo as fases de } \\
\text { desenvolvimento dos } \\
\text { alunos. } \\
\text { Art. } 18 . \text { O ensino de } \\
1^{\circ} \text { grau terá a duração } \\
\text { de oito anos letivos } \\
\text { e compreenderá, } \\
\text { anualmente, pelo } \\
\text { menos } 720 \text { horas de } \\
\text { atividades. } \\
\text { equivalentes. }\end{array}$ & $\begin{array}{l}\text { Art. } 1^{\circ}-\text { A educa- } \\
\text { ção abrange os pro- } \\
\text { cessos formativos } \\
\text { que se desenvolvem } \\
\text { na vida familiar, } \\
\text { na convivência hu- } \\
\text { mana, no trabalho, } \\
\text { nas instituições de } \\
\text { ensino e pesquisa, } \\
\text { nos movimentos so- } \\
\text { ciais e organizações } \\
\text { da sociedade civil e } \\
\text { nas manifestações } \\
\text { culturais. } \\
\text { Art. } 2^{\circ} \text { - A edu- } \\
\text { cação, dever da } \\
\text { família e do Estado, } \\
\text { inspirada nos prin- } \\
\text { cípios de liberdade } \\
\text { e nos ideais de soli- } \\
\text { dariedade humana, } \\
\text { tem por finalidade } \\
\text { o pleno desenvolvi- } \\
\text { mento do educando, } \\
\text { seu preparo para } \\
\text { o exercício da } \\
\text { cidadania e sua } \\
\text { qualificação para o } \\
\text { trabalho. }\end{array}$ & $\begin{array}{l}\text { Art. } 3^{\circ} \text { - Art. } 32 \\
\text { passa a vigorar com } \\
\text { a seguinte redação: O } \\
\text { ensino fundamental } \\
\text { obrigatório, com dura- } \\
\text { ção de } 9 \text { (nove) anos, } \\
\text { gratuito na escola pú- } \\
\text { blica, iniciando-se aos } \\
6 \text { (seis) anos de idade, } \\
\text { terá por objetivo a } \\
\text { formação básica do } \\
\text { cidadão, mediante [...] }\end{array}$ \\
\hline $\begin{array}{l}\text { Idade de } \\
\text { ingresso e } \\
\text { término }\end{array}$ & $\begin{array}{l}7 \text { - } 10 \text { anos (podendo esten- } \\
\text { der até } 12 \text { anos) } \\
\text { Art. 26. - O Ensino Primário } \\
\text { será ministrado, no mínimo, } \\
\text { em quatro séries anuais. } \\
\text { Parágrafo único. Os sistemas } \\
\text { de ensino poderão estender } \\
\text { a sua duração até seis anos, } \\
\text { ampliando, nos dois últimos } \\
\text { [...] } \\
\text { Art. } 27 . \text { O Ensino Primário } \\
\text { é obrigatório a partir dos } 7 \\
\text { anos e só será ministrado na } \\
\text { língua nacional. }\end{array}$ & $\begin{array}{l}7 \text { - } 14 \text { anos } \\
\text { Art. } 19 . \text { - Para o } \\
\text { ingresso no ensino } \\
\text { de } 1^{\circ} \text { grau, deverá } \\
\text { o aluno ter a idade } \\
\text { mínima de } 7 \text { anos. }\end{array}$ & $\begin{array}{l}\text { 7- } 14 \text { anos } \\
\text { Com indicativo da } \\
\left.\text { Lei } n^{\circ} .11 .114 / 2005\right) \\
\text { para matrícula aos } \\
6 \text { anos na primeira } \\
\text { série do fundamen- } \\
\text { tal. }\end{array}$ & $\begin{array}{l}6 \text { - } 14 \text { anos } \\
\text { Art. } 87 \S 2^{\circ}-\text { O poder } \\
\text { público deverá recen- } \\
\text { sear os educandos no } \\
\text { Ensino Fundamental, } \\
\text { com especial atenção } \\
\text { para o grupo de } 6 \\
\text { (seis) a } 14 \text { (quatorze) } \\
\text { anos de idade e de } 15 \\
\text { (quinze) a } 16 \text { (dezes- } \\
\text { seis) anos de idade. } \\
\text { I - matricular todos os } \\
\text { educandos a partir dos } \\
6 \text { (seis) anos de idade } \\
\text { no Ensino Fundamen- } \\
\text { tal [...] }\end{array}$ \\
\hline
\end{tabular}


Quadro 1. Evolução do Ensino Fundamental brasileiro (continuação)

\begin{tabular}{|c|c|c|c|c|}
\hline Tratamento & Anos & Séries & Séries & Anos \\
\hline $\begin{array}{c}\text { Tempo } \\
\text { previsto de } \\
\text { escolaridade }\end{array}$ & $\begin{array}{l}4 \text { anos (podendo se estender } \\
\text { por mais dois anos) }\end{array}$ & $\begin{array}{l}8 \text { anos } \\
\text { Art.18 - O ensino de } \\
1^{\text {o }} \text { grau terá a duração } \\
\text { de oito anos letivos } \\
\text { e compreenderá, } \\
\text { anualmente, pelo } \\
\text { menos } 720 \text { horas de } \\
\text { atividades. }\end{array}$ & $\begin{array}{l}8 \text { - } 9 \text { anos } \\
\text { Art. } 32 . \text { - O Ensino } \\
\text { Fundamental, com } \\
\text { duração mínima de } \\
\text { oito anos, obri- } \\
\text { gatório e gratuito } \\
\text { na escola pública, } \\
\text { terá por objetivo a } \\
\text { formação básica do } \\
\text { cidadão [...] }\end{array}$ & $\begin{array}{l}9 \text { anos } \\
\text { Art. } 3^{\circ} \text { O art. } 32 \text { da } \\
\text { Lei } n^{\circ} .9 .394 \text {, de } 20 \\
\text { de dezembro de } 1996 \text {, } \\
\text { passa a vigorar com } \\
\text { a seguinte redação: } \\
\text { “Art. } 32 . \text { O Ensino } \\
\text { Fundamental obriga- } \\
\text { tório, com duração de } \\
9 \text { (nove) anos, gratuito } \\
\text { na escola pública, } \\
\text { iniciando-se aos } 6 \\
\text { (seis) anos de idade, } \\
\text { terá por objetivo a } \\
\text { formação básica do } \\
\text { cidadão”. }\end{array}$ \\
\hline $\begin{array}{c}\text { Organização } \\
\text { do sistema de } \\
\text { ensino }\end{array}$ & Ciclos & $\begin{array}{l}\text { Séries iniciais e } \\
\text { finais } \\
\text { Art. } 5^{\circ} \text { - No ensino } \\
\text { de primeiro grau, a } \\
\text { parte de educação } \\
\text { geral seja exclusiva } \\
\text { nas séries iniciais e } \\
\text { predominantes nas } \\
\text { finais }[. . .]\end{array}$ & $\begin{array}{l}\text { Séries anuais, } \\
\text { períodos semestrais, } \\
\text { ciclos } \\
\text { Art.23 - séries } \\
\text { anuais, períodos } \\
\text { semestrais, ciclos, } \\
\text { alternância regular } \\
\text { de períodos de } \\
\text { estudos, grupos } \\
\text { não seriados, com } \\
\text { base na idade, na } \\
\text { competência e em } \\
\text { outros critérios, ou } \\
\text { por forma diversa } \\
\text { de organização, } \\
\text { sempre que o inte- } \\
\text { resse do processo de } \\
\text { aprendizagem assim } \\
\text { o recomendar. }\end{array}$ & Idem 9394/96 \\
\hline
\end{tabular}


Quadro 1. Evolução do Ensino Fundamental brasileiro (continuação)

\begin{tabular}{|c|c|c|c|c|}
\hline Currículo & $\begin{array}{l}\text { Art. 25. - O Ensino Primário } \\
\text { tem por fim o desenvolvi- } \\
\text { mento do raciocínio e das } \\
\text { atividades de expressão da } \\
\text { criança, e a sua integração no } \\
\text { meio físico e social. }\end{array}$ & $\begin{array}{l}\text { Art. } 4^{\circ}-\text { Os currícu- } \\
\text { los do ensino de } 1^{\circ} \\
\text { e } 2^{\circ} \text { graus terão um } \\
\text { núcleo comum, obri- } \\
\text { gatório em âmbito } \\
\text { nacional, e uma parte } \\
\text { diversificada para } \\
\text { atender, conforme as } \\
\text { necessidades e possi- } \\
\text { bilidades concretas, } \\
\text { às peculiaridades } \\
\text { locais, aos planos dos } \\
\text { estabelecimentos e às } \\
\text { diferenças individu- } \\
\text { ais dos alunos. I - O } \\
\text { Conselho Federal de } \\
\text { Educação fixará para } \\
\text { cada grau as matérias } \\
\text { relativas ao núcleo } \\
\text { comum, definindo- } \\
\text {-lhes os objetivos e a } \\
\text { amplitude }\end{array}$ & $\begin{array}{l}\text { Art. } 26 \S 1^{\circ}-\mathrm{O} \\
\text { estudo da língua } \\
\text { portuguesa e da ma- } \\
\text { temática, o conhe- } \\
\text { cimento do mundo } \\
\text { físico e natural e da } \\
\text { realidade social e } \\
\text { política, especial- } \\
\text { mente do Brasil. }\end{array}$ & Idem 9394/96 \\
\hline
\end{tabular}

Fonte: Elaborado pela autora

Quadro 2 Comparação entre o Ensino Fundamental de 8 anos (LDB nº. 9394/1996) e Ensino Fundamental de 9 anos (LDB nº. 11.274/2006)

\begin{tabular}{|c|c|c|}
\hline $\begin{array}{l}\text { Ensino Fundamental } 8 \text { anos } \\
\qquad\left(L D B n^{\circ} 9394 / 1996\right)\end{array}$ & $\begin{array}{l}\text { Ensino Fundamental } 9 \text { anos } \\
\left(L D B n^{\circ} 11.274 / 2006\right)\end{array}$ & Idade dos alunos \\
\hline Fase III - Educação Infantil & $1^{\circ}$ ano (EF9 anos) & 6 \\
\hline 1ª série (EF8 anos) & $2^{\circ}$ ano (EF9 anos) & 7 \\
\hline 2ª série (EF8 anos) & $3^{\circ}$ ano (EF9 anos) & 8 \\
\hline $3^{\mathrm{a}}$ série (EF8 anos) & $4^{\circ}$ ano (EF9 anos) & 9 \\
\hline 4ª série (EF8 anos) & $5^{\circ}$ ano (EF9 anos) & 10 \\
\hline 5ª série (EF8 anos) & $6^{\circ}$ ano (EF9 anos) & 11 \\
\hline 6ª série (EF8 anos) & $7^{\circ}$ ano (EF9 anos) & 12 \\
\hline 7ª série (EF8 anos) & $8^{\circ}$ ano (EF9 anos) & 13 \\
\hline 8a série (EF8 anos) & $9^{\circ}$ ano (EF9 anos) & 14 \\
\hline
\end{tabular}

Fonte: Elaborado pela autora 
Dentre seus resultados, aponta a grande presença feminina na profissão, mas ressalta que esse dado não revela homogeneidade, e sim diferenças significativas no que diz respeito ao nível socioeconômico e familiar dessas professoras, que, oriundas de classes mais baixas, buscam, na profissão, a ascensão social que as libera das obrigações do lar, sendo um universo privilegiado, tanto para as que querem ingressar no mundo do trabalho, tendo uma condição social melhor, quanto para as que consideram a possibilidade de aumentar os rendimentos, e aí se inclui a questão da sobrevivência via profissão não manual:

[...] Para parte desse professorado, o salário é ainda um complemento de um processo de incorporação social, mas, para a maioria, o salário é fundamental para a manutenção da família, que dele depende em escala cada vez maior. Embora genericamente com suas expectativas insatisfeitas, essas não têm a mesma natureza para todas as docentes. Para as mais bem situadas socialmente, as expectativas relatadas são mais idealizadas, associadas a propostas de fazer com que as crianças aprendam a ter reconhecimento social. Para aquelas cujo nível socioeconômico familiar é mais baixo, as expectativas estão relacionadas à contribuição da profissão para o rendimento familiar. (GATTI, 1996, p.86).

Cunha (1999) complementa a questão da "feminização" do magistério, pontuando que

[...] A presença feminina na profissão docente, em especial na Educação Infantil, é um fenômeno quase universal. Certamente, essa relação histórica se relaciona com a combinação que se dá entre maternidade e catequese, tendo como referencial o objetivo da educação e escola. Além disso, a sociedade de valores preponderantemente masculinos faz concessão ao trabalho feminino, quando se trata de crianças e enfermos, a partir de um referencial especificamente moral. Revendo a história da atividade docente, é fácil encontrar indícios de que as competências e requisitos para esta profissão ligavam-se às evidencias de um comportamento quase puritano. Mais do que condições que levassem os alunos a aprender, as professoras tinham que demonstrar padrões tradicionais de conduta, inclusive no vestir (CUNHA, 1999, p. 138-9).

Além das considerações acerca da feminização do magistério, vimos ainda, nas tabelas 1 e 2 , a idade cronológica das professoras e gestoras do município que estão à frente do primeiro ano do Ensino Fundamental, bem como o tempo de experiência que possuem na área de Educação, especialmente no trabalho com a idade de 6 anos: são professoras que têm mais de 40 anos de idade e mais de 24 anos de carreira. Salvo Leila (EMR), que não teve experiência anterior com crianças de 6 anos na Educação Infantil, as demais têm experiência de mais de 10 anos nessa área.

Na escola particular, a professora Rute (EPC) tem 15 anos de experiência com crianças de 6 anos - 5 anos já neste novo Ensino Fundamental, praticamente desde o início da mudança, em 2006. As demais professoras têm 2 anos de experiência com crianças no Ensino Fundamental.

Nas falas das entrevistadas, percebe-se que a prática de anos no magistério, bem como a experiência como professoras na Educação Infantil (com crianças de 6 anos) e a experiência das gestoras, não garantiram o conhecimento necessário sobre como deveria ser o trabalho com as crianças dessa faixa etária no primeiro ano do Ensino Fundamental. A professora Silvana (EMP) confirma a necessidade de mais orientação no trabalho: 
[...] nós, professoras do primeiro ano, vamos ter agora a apostila do positivo, não sei [...] a prefeitura está implantando também porque até então nós não tínhamos material [...] o material ainda não chegou, não vi, não conheço, mas é um caminho [...] (SILVANA, EMP).

A gestora Débora (EMP) posiciona-se quanto aos conteúdos do material citado pela professora Silvana (EMP), demonstrando, ao mesmo tempo, conhecimento e desconhecimento: "Foram reformulados. Eles fizeram como uma mediação, no que eles trabalhavam com a terceira fase, se adequando ao primeiro ano [...] Ainda não vi o material".

Esperava-se que, por terem experiência com crianças do Jardim III, se sairiam bem com as do primeiro ano. E não parece estar ocorrendo isso. No município pesquisado, houve um movimento de acomodação dos profissionais que possuem o "perfil" descrito nas tabelas 1e 2 no primeiro ano do Ensino Fundamental, visto que se considerava que eles teriam maior probabilidade de cumprir as funções para o cargo ocupado.

Essas expectativas, que incluem um suporte básico anterior - ancorado na experiência com crianças de 6 anos -, provável conhecimento das necessidades dessa faixa etária, bem como do próprio desenvolvimento biopsíquicossocial, encontram voz em Dubar (2005), quando este discute a "construção da identidade" na relação com as instituições. Dubar (2005) apresenta dois processos heterogêneos, que são considerados como categorias socialmente disponíveis para definição dos mecanismos identitários. Assim,

[...] O primeiro concerne à atribuição da identidade pelas instituições e pelos agentes que estão em interação direta com os indivíduos. Só pode ser analisado no interior dos sistemas de ação nos quais o indivíduo está implicado, e resulta de

\begin{abstract}
"relações de força" entre todos os atores envolvidos e dá legitimidade [...] O segundo processo concerne à interiorização ativa, à incorporação da identidade pelos próprios indivíduos. Ela só pode ser analisada no interior das trajetórias sociais pelas e nas quais os indivíduos constroem "identidades para si", que nada mais são a história que eles contam sobre o que são (DUBAR, 2005, p.139)
\end{abstract}

Desse modo, é interessante questionar a identidade desses profissionais professores, a quem, na dinâmica com a (e da) organização, no caso a escola, são atribuídas responsabilidades e funções que, somadas à sua biografia, ao contexto, ao meio social, bem como às relações estabelecidas ao longo da trajetória de sua carreira, acabam sendo incorporadas, de maneira que eles respondem não só àquilo que lhes foi atribuído (do outro para si), como também ao que assumiram (de si para o outro), resultado de sua identificação com a escola e com sua própria função.

Em relação à possibilidade de tais professores - oriundos do segmento Infantil e com experiências com crianças de 6 anos - terem se deslocado para o segmento Fundamental não apenas em busca de um novo espaço físico de trabalho, mas também de uma outra relação com o trabalho já vivenciado, Dubar (2005) ainda esclarece que esses processos, de "atribuição" e "incorporação", podem provocar "divergência" entre a identidade que é conferida a uma pessoa ("social virtual”) e a que a própria pessoa se atribui (“social real”).

Considerando o trânsito desses professores e gestoras, não apenas no aspecto do segmento que trabalhavam - (do Infantil para ao Fundamental) - como também da nova perspectiva identitária profissional que emerge, Ferreira (2008) afirma que, ao longo das décadas, as reformas educativas têm causado efeitos nas subjetividades dos professores. Esses efeitos ocorrem também no âmbito 
da gestão: "gestores, decisores, planejadores e formadores" se incumbem da tarefa de ser "professores de professores", tratando de "ações de formação", definindo prioridades, cursos, atividades e programas de formação para os docentes. Estes, em contrapartida, ficam em uma situação de "formandos-alunos", assumindo o papel de "carentes de formação", e sofrem com o pressuposto de que, sendo alunos, não são considerados sujeitos de sua formação, de modo que as mudanças passam essencialmente pela gestão. Essa afirmativa encontra voz nas falas das professoras e gestoras quando estas foram arguidas sobre a lei 11. 274/2006 e seus objetivos:

O que eu me lembro é que existia uma palestra, a prefeitura falou sobre isto, mas deu para um grupo seleto, que seriam coordenadores e diretores [...] Professores, não! [...] Tem um conhecimento assim: que, com esta lei, as crianças tinham que ir para o Fundamental com 6 anos (LEILA, EMR).

Almeida (2006, p.103) sinaliza que [...] "se não houver envolvimento e a real participação dos professores, as transformações não ocorrerão". Essa lógica traz embutido um modelo do profissional professor que é esvaziado da condição de protagonista no processo de mudança e colocado à espera que lhe digam o que e como fazer para efetivar a reforma.

Débora (EMP) e Lina (EMQ), gestoras das escolas municipais pesquisadas, assim como Clara (EPC), da escola particular, também confirmam que não tiveram orientação dos órgãos competentes. Lina (EMQ) demonstra que tem um conhecimento de quando trabalhava no segmento do Infantil, mas que não tem a certeza de que os professores de sua escola conheçam a lei:

[...] Não sei se esta escola teve acesso na época. Eu conheci porque estava no
Infantil e estava participando desta formação, desta transição [...] às vezes até pelas atitudes que algumas professoras tomam, eu acho que não conhecem tanto assim, não sabem (LINA, EMQ)

[...] não foi nada da Secretaria da Educação. Nunca ninguém entrou em contato com a gente, e a gente também não entrou em contato com ninguém [...] A gente está trabalhando muito assim, na expectativa, o que a criança pode nos apresentar. (Clara, EPC)

Em termos burocráticos, nós temos os nossos supervisores de ensino, do Fundamental, cada segmento tem o seu supervisor de ensino [...] nós, gestores da escola, apenas somos direcionados para conhecimento, trabalho [...] Estudo de lei, apenas quando isso está no momento. (DÉBORA, EMP)

As maneiras como as escolas públicas e particulares trabalharam o "trânsito", ou melhor, o deslocamento das crianças de 6 anos para o primeiro ano do Ensino Fundamental foram semelhantes. De modo geral, tanto em algumas das escolas públicas quanto na particular, tentou-se fazer com que as crianças oriundas da Educação Infantil tivessem um contato inicial com o que seria o primeiro ano do Ensino Fundamental:

No ano passado, nós fizemos já um trabalho de trazer as crianças da Emei para o Fundamental. Então as professoras daqui prepararam a recepção das crianças, acolheram, mostraram como era [...] Isso ajudou muito (SILVANA, EMP)

Com a ponte [...] o ano passado [...] uma tentativa da secretaria [...] é que os professores da segunda fase tivessem contato com os do primeiro ano. Só isso [...] a secretaria tentou fazer um bate-bola entre EMEI e EMEF, de professoras de 5 anos e 6 anos para criar uma ponte, o que precisava e não precisava (LEILA, EMF). 
No fim do ano, a professora do segundo ano começa a vir bastante no pré. O ano passado, nós fizemos assim: levei as crianças, e a professora do segundo ano preparou uma atividade, mostrou a classe, contou que agora não precisa ficar preocupado, que tem hora do lanchinho, sai mais cedo [...] Foram umas três vezes para o segundo ano [...] e a professora do nível II, do Infantil, mandou uma tarde os alunos pra mim (RUTE, EPC).

Rute (EPC), professora da escola particular, que está à frente do primeiro ano e anteriormente era do Jardim III (última fase da Educação Infantil, anterior à lei 11.274/2006), sem perceber denuncia em sua fala um aspecto que estará presente em todo o seu discurso, demonstrando que concepção de professor e de ensino possui. Quando reconhece sua turma como "pré" e não como "primeiro ano", está incorporada aí a visão de ser esse primeiro o antigo pré (como pré-primário). Assim, volta-se à década de 1960 , o que remete à Lei $n^{\circ} 4.024 / 61$, em que o pré-primário é instituído legalmente. A professora fala naturalmente, mesmo já tendo havido mudança de nomenclatura em sua sala, designada "primeiro ano do Ensino Fundamental”. Não reconhece o equívoco que comete quando, na sequência, diz que seus alunos visitaram a classe da professora do segundo ano. Se prestasse atenção, veria que não há sentido em levar crianças do pré para o segundo ano.

No que diz respeito ao espaço físico, que envolve pátio, salas de aula, cantina, sanitários etc., tanto na escola particular quanto na pública há evidências de problemas.

Na escola particular, devido ao fato de a escola ser constituída de uma única construção, com blocos que se separam nos segmentos Infantil, Fundamental e Médio, há uma facilidade no trânsito que permite o deslocamento e a comunicação entre os profissionais. Isso absolutamente não significa afirmar que, por conta dessa condição, ocorra um trabalho adequado em termos de integração e planejamento entre os segmentos. O espaço físico em que as crianças do primeiro ano ficam é o mesmo do Infantil, com estrutura de parque (areia, escorregador, balanço, árvore). Só “assumem” o Ensino Fundamental, de fato, quando entram no segundo ano. Neste, a configuração é diferente: não há mais acesso ao parquinho. Há uma cantina e uma quadra poliesportiva para todos os alunos do Fundamental I (crianças dos 6 aos 14 anos), que se dividem ao longo da semana para sua utilização em horários preestabelecidos em uma planilha. Assim, a mudança para as crianças do primeiro ano ocorre quando elas finalmente migram para o espaço do Fundamental. Ou seja, há um atraso de um ano para ingresso no espaço físico do segmento Fundamental, diferentemente das crianças das EMEI, que não têm escolha e que, aos 6 anos, querendo ou não, estão em outro espaço desconhecido e que, definitivamente, é o do Ensino Fundamental.

Na escola pública, não há como o aluno permanecer no espaço anterior: ele deverá fazer sua caminhada para o Fundamental tão logo termine a fase II. Assume esse segmento de ensino sem “maquiagens", estando mais aberto, aos 6 anos, a todo tipo de sentimento e situação que uma mudança de fato gera, diferentemente dos alunos da escola particular.

Nesse sentido, segundo o que se observou nesta pesquisa, parece que, para as crianças das EMEI, mudar de uma vez é melhor, considerando as condições em que essa mudança ocorre. Não mudar de espaço físico aos 6 anos, permanecendo na ala do infantil, e ser cobrado de toda sorte de responsabilidades que o segmento Fundamental já exige é algo discutível, pois a criança está em um espaço que clama por situações mais 
descontraídas, ao mesmo tempo que a sala de aula lhe exige mais tempo nas tarefas, mais concentração e mais responsabilidades, que não cabem mais na estrutura do Infantil.

No que diz respeito à estrutura das EMEIs, encontram-se diferenças entre elas quanto ao espaço físico, que vão desde escolas com parque, árvores, balanços, área verde, mobiliário adequado específico para a idade de 6 anos, até escolas em que o espaço externo é apenas um pátio cimentado e a organização da estrutura física é aproveitada para atender a crianças de diferentes idades, que dividem as mesmas salas de aula em diferentes períodos. A seguir, veremos duas realidades opostas, apresentadas pelas gestoras:

[...] aqui na escola, nós somos premiadas, temos um parque, o espaço físico é maravilhoso, eles vão às árvores fazer leitura com as professoras, a sala de informática, amam de paixão (DÉBORA, EMP).

[...] a minha estrutura é horrível. A estrutura não ajuda, eu queria muito um parquinho aqui, não tenho, ainda; vou ter [...] já cimentei [...] o mobiliário é grande para eles [...] a mesma turma que de manhã é o quarto ano, é o primeiro ano à tarde [...] A carteira é enorme [...] Os pés ficam suspensos, balançando no ar [...] Não tem espaço físico para ser exclusivo de primeira série [...] A pintura está horrível [...] A sala não tem graça, não é aconchegante (LINA, EMQ).

Em relação ao encaminhamento dos trabalhos com o primeiro ano, fica claro, pela fala das participantes, que existe contradição quanto ao entendimento do que é o primeiro ano, tanto pelas professoras quanto pelas gestoras. Algumas apontam que o primeiro ano do Ensino Fundamental de nove anos, assim como o seu conteúdo, é o mesmo que o da primeira série do antigo Ensino
Fundamental de oito anos; outras afirmam que o primeiro ano do Ensino Fundamental de nove anos é o mesmo Jardim III ou fase III da Educação Infantil. Há também as que dizem que não é nem o Jardim III, nem a antiga primeira série. É o que, então?

[...] são crianças da fase três [...] para nós o maior problema é esse, que o professor entenda que eles ainda têm mais um ano para se alfabetizar [...] Isso não está claro, eles acham que esse primeiro ano é a antiga primeira série e eles esquecem que é a antiga fase 3 [...] Não pode ser nem conteúdo de uma fase 3 , nem da antiga primeira série [...] Nem a lei deixou claro isso, né? (LINA, EMQ).

[...] quando eu dava aula para criança de terceira fase, 6 anos, na prefeitura, a gente esperava muito menos dele do que agora, porque a gente começava o caderno só em agosto, porque achava que ele não tinha condição, e hoje, na prefeitura, na segunda fase já há uma cobrança maior, a gente percebe o desenvolvimento da criança no Fundamental, a cobrança já começou antes, já com 4 anos [...] As crianças estão chegando melhor no Fundamental [...] Os que eles estão fazendo hoje com 6 anos aqui no Fundamental, antes não faziam. Tudo foi antecipado [...] Antecipou na préescola, então o trabalho de terceira fase está sendo feito na segunda (MAURA, EMS).

[...] Conteúdo [...] Muito próximo de uma terceira fase, que a gente já tem experiência do que era uma terceira fase aqui [...] Preparo para uma antiga primeira série, está tendo essa preocupação, sim [...] (SILVANA, EMP).

A fala de Silvana (EMP) denuncia a questão de ser uma "primeira série antiga". Dessa forma, a concepção de ensino que vigora versa ainda sobre a Lei ${ }^{\circ}$ 5.692/71, em que foi instituída a primeira série do primeiro grau, na qual os conteúdos deveriam ser 
vencidos em oito anos e não em nove, de maneira que há uma exigência velada maior para as crianças do novo Ensino Fundamental.

Arelaro, Jacomini e Klein (2011) apontam as consequências dessas mudanças:

[...] Diante das mudanças anunciadas e do processo de implantação verificado até então, é possível sustentar que o Ensino Fundamental de nove anos não representa, necessariamente, um ganho na educação de crianças pequenas. Ao contrário, diante das expectativas socialmente construídas pelos pais e pelas orientações e exigências das redes de ensino, muitas crianças de 6 anos têm sido submetidas a um regime de trabalho escolar incompatível com a faixa etária (ARELARO; JACOMINI; KLEIN, 2011, p.48)

É interessante notar uma observação fortemente sinalizada por professoras e gestoras em relação à implantação da Lei $n^{\circ}$ 11.274/2006, especialmente para a criança de 6 anos: a preocupação em definir quando será o momento certo para a alfabetização, como se fosse este o objetivo maior, em detrimento dos demais objetivos relativos à inclusão.

[...] nós sofremos mais no primeiro ano [...] Com os pais que acharam um absurdo, ficou assim: os pais falavam que ele ia para o primeiro ano direto, ia pular uma etapa da vida (Débora, EMP).

[...] as mães falavam assim, é primeiro ano [...] elas confundem bastante! Para a gente pôr na cabecinha delas que não é primeira série [...] as mães falam: mas ele está indo assim tão novinho [...] vai ter que aprender 0 ano que vem, como assim? Ele vai ter que ler? [...] eu acho que para muitas professoras que são esclarecidas teve isso também, que puxaram os conteúdos da primeira série (SILVANA, EMP).
[...] também para as professoras que estão há anos no Fundamental e pegam a criança da antiga terceira fase e ficam na dúvida se eu vou alfabetizar ou eu vou dar atividades da pré-escola (DÉBORA, EMP).

Um ponto crítico levantado por Leila (EMR) diz respeito ao fechamento das salas de aula da fase III, nas EMEI, e também à fase anterior (II), das crianças de 5 anos, cujo professor ficou sem orientação: se alfabetiza ou não, se introduz a letra cursiva ou não, que conteúdo trabalhar... e continua ainda a discussão sobre alfabetização:

[...] Os professores também não gostaram porque primeiro na EMEI ia fechar uma sala; segundo, o que fazer com essas crianças? Então eles iam para o Fundamental e fazia o que com a segunda fase? Vou ter que descaracterizar a segunda fase? Daí ficou aquela coisa, além da preocupação com o conteúdo, a preocupação com a letra, com o tipo de letra, alfabetização [...] deu um nó na cabeça do professor (LEILA, EMR).

Do grupo de professoras, Leila (EMR) sempre foi a mais inflamada em relação às questões que permeiam a mudança. No momento em que se passou das questões técnicas que envolvem a mudança para a sua opinião, ela afirmou não ter gostado da mudança e começou a trazer à tona um problema que ficou caracterizado na rede pública como a "criança do pulo":

[...] em educação não dá para ficar brincando muito, que nem quando teve 0 PULO, essas crianças que pularam uma fase e pularam mesmo são crianças na rede que dão trabalho e vão dar trabalho até sair [...] essas salas serão sempre nosso problema, é a sala do pulo, queimaram etapa (LEILA, EMR).

No ano em que se instaurou a mudança legal, muitas crianças que, aos 6 
anos, estavam na Educação Infantil, na fase III, não foram matriculadas na Educação Infantil e sim no primeiro ano do Ensino Fundamental. Os pais diziam que essa medida seria para já começarem a "se acostumar" com o novo segmento.

Isso ocorreu em muitas escolas particulares de Educação Infantil, especialmente as que só ofereciam pré-escola e não tinham a continuidade dos segmentos: algumas perderam muitos alunos e outras fecharam suas portas.

Nas EMEIs também não foi diferente: alguns pais quiseram levar os filhos que tinham terminado a fase II para o primeiro ano do Ensino Fundamental, porque isso era possível, mesmo ainda havendo a possibilidade de a criança estudar até os 6 anos no Infantil III, no período conhecido por "transição da lei”, que terminava em 2010.

$\mathrm{Na}$ verdade, dois segmentos correram paralelamente e atendiam a crianças de 6 anos: o Infantil, com a fase III, e o Fundamental, com o primeiro ano.

Como a mudança tinha o prazo até 2010 para ser definitivamente instaurada, quando as crianças que aos 6 anos permaneceram na fase III do segmento Infantil foram para o Fundamental, no ano seguinte, aos 7 anos, matricularam-se no segundo ano, e não no primeiro, visto que o primeiro ano era o compatível com a idade dos alunos da fase III.

Essas crianças ficaram estigmatizadas como "crianças do pulo", por terem "pulado o primeiro ano e seguirem com o segundo". Mas não houve pulo de fato, embora pareça ter acontecido isso. O que ocorreu foi um ajuste: se elas estavam na fase III aos 6 anos, evidentemente deveriam ir para a turma de 7 anos, o que, na nova configuração do ensino, compete ao segundo ano do Fundamental.

Porém, muito se discutiu a respeito, dizendo-se que houve uma defasagem de conteúdo, haja vista que o que estava definido para ser trabalhado na fase III do Infantil era diferente do conteúdo do primeiro ano do Fundamental e que essas crianças sofreriam perdas significativas em sua aprendizagem. Essa “confusão" série-idade pode ser consultada no Quadro 2 apresentado anteriormente.

Embora isso seja um equívoco, pois o "segundo ano" do Ensino Fundamental de nove anos representava, em tese, a primeira série do antigo Ensino Fundamental de oito anos, muitos pais e até mesmo professores não compreenderam a transição. Nos livros didáticos e apostilas, havia duas nomenclaturas: segundo ano do Ensino Fundamental de 9 anos e primeira série do Ensino Fundamental de 8 anos, de modo que as pessoas se situassem quanto à mudança que ainda estava em processo.

Mais que isso, deveria haver um ajuste entre a fase III do Infantil e o primeiro ano do Ensino Fundamental de 9 anos: se o pai resolvesse antecipar a saída do filho da escola, ao término do Infantil II, de 5 para 6 anos, e o matriculasse já no primeiro ano do "novo" Ensino Fundamental, deveria ser garantida uma continuidade - não só uma continuidade no trabalho com os alunos de 6 anos, mas também uma unidade de organização curricular para todo o segmento Fundamental, conforme se confirma a seguir:

[...] Nossa experiência na escola mostra-nos que a criança de 6 anos encontra-se no espaço de intersecção da Educação Infantil com o Ensino Fundamental. Sendo assim, o planejamento de ensino deve prever aquelas diferenças e também atividades que alternem movimentos, tempos e espaços. É importante que não haja rupturas na passagem de educação infantil para o ensino fundamental, mas que haja continuidade dos processos de aprendizagem (GOULART, 2007, p.87) 
Quando Leila (EMR) afirma que houve perdas para essas crianças e justifica sua indignação dizendo que essas serão as crianças marcadas, que sempre trarão problema na rede, ela apresenta uma alternativa de maior investimento na Educação Infantil, na formação do professor, e assume a alfabetização como um problema sem orientação:

[...] Eu não gostei [...] Porque a fundamentação deles, alegar que é para acabar com o analfabetismo, por que eles não fortaleceram mais a Educação Infantil que a criança ia estar dentro de uma escola na qual ia ser legal para ela? [...] Aumentaram um ano [...] alfabetizar não é fácil, é muito complicado, você vai dando tiros para tudo quanto é lado [...] (LEILA, EMR).

É necessário discutir o horizonte da cultura e da história de maneira que, estando a criança em um ou outro segmento, sejam garantidas a ela dimensões maiores, que não fiquem limitadas apenas à preocupação de onde a alfabetização ocorre e como deve ser realizada, conforme expresso pela professora Leila (EMR).

A partir do momento em que se considerar e/ou perceber que Educação Infantil e Ensino Fundamental são indissociáveis, envolvem afetos, saberes, valores, conhecimentos, atenção, e que ambos têm por objetivo assegurar a apropriação e a construção de conhecimentos, a compreensão do significado do Ensino Fundamental de nove anos provavelmente ficará mais clara para todos - professores, gestores, pais, comunidade. $\mathrm{O}$ precisa ser garantido é o atendimento das necessidades das crianças.

Outras tantas reflexões dos professores e gestores acerca do impacto trazido pela lei $11.274 / 2006$ ao município estudado podem ser encontradas neste texto de Cecília Hashimoto: Ensino Fundamental de nove anos: um novo caminho em velha estrada?
Um velho caminho em nova estrada? (ver Referências bibliográficas).

\section{Conclusões e considerações finais}

De maneira geral, percebeu-se, nesta pesquisa, que não se estabeleceu o diálogo entre dois níveis de ensino, o Infantil e o Fundamental, para realizar a passagem da criança de 6 anos para o Ensino Fundamental.

Destacou-se também que, mesmo com a quantidade de manuais, emendas, pareceres, documentos orientadores e norteadores oriundos do processo de implantação da Lei $n^{0} 11.274 / 2006$, não houve tempo suficiente e para discussão, compreensão das medidas e nem a formação dos professores com vistas ao novo formato do ensino.

Outro aspecto muito forte desta pesquisa diz respeito à formação dos professores, visto que, dos sete entrevistados, seis deles, oriundos da Educação Infantil, têm curso de pós-graduação a distância, têm experiência com crianças de 6 anos e, assim mesmo, apresentam muitas dúvidas quanto ao trabalho que deve ser desenvolvido com o primeiro ano do Ensino Fundamental. Os achados da pesquisa indicaram que a prática de vinte anos no magistério da maioria das entrevistadas, a experiência como professoras na Educação Infantil com crianças de 6 anos e a experiência das gestoras também no segmento Infantil não garantiram 0 conhecimento necessário sobre o que deve ser o trabalho com as crianças de dessa faixa etária no Ensino Fundamental. Devido à quantidade de dúvidas que apresentaram com as questões relativas ao desenvolvimento do trabalho (incluindo a escolha de conteúdos) com o primeiro ano do Ensino Fundamental, afirma-se aqui que a saída é a formação continuada desses profissionais. Apenas a formação inicial (curso de 
Pedagogia) não é suficiente; tampouco uma pós-graduação.

Notou-se que há um descompasso em relação à Lei $n^{\circ} 11.274 / 2006$, seus pareceres e instrumentos decorrentes, visto que a falta de conhecimento e discussão dessas diretrizes e orientações permitiu e permite que cada um faça seu trabalho de acordo com suas convicções, calcadas em uma prática de ensino que tem suas raízes no segmento Infantil, e acaba sendo adaptada ao Fundamental.

O primeiro ano do Ensino Fundamental de nove anos ora se revela como a terceira fase do segmento Infantil, "maquiada" de Fundamental, ora como uma antiga primeira série do segmento Fundamental das Leis 5.692/71 e 9.394/96 - que não sabe o que fazer com a criança de 6 anos, visto que seu trabalho era com crianças de 7.

Há necessidade de se questionar, inclusive, a identidade desse Ensino Fundamental de nove anos, trabalhando de forma coletiva - com equipes de apoio, professores, gestores - em horários de estudo dentro da escola, no ambiente de trabalho, com reuniões semanais, discussões, estudos de caso, de modo que se esclareça efetivamente qual deve ser a abordagem desse ensino e quais devem ser seus objetivos.

Apenas incorporar crianças de 6 anos no Ensino Fundamental, sem que essa medida seja compreendida, absorvida e internalizada por aqueles que deverão atender à determinação, ou seja, professores e gestores, não cumpre o objetivo de uma escola de qualidade para todos, preconizada pelos documentos oficiais do MEC.

No município pesquisado, notou-se a falta de diversos elementos. A compreensão dos objetivos da mudança; a apropriação dos encaminhamentos da criança de 6 anos no Ensino Fundamental; a formação de um grupo de professores que garanta esse "trânsito" de mudança de maneira equilibrada e coerente; o conhecimento do material de apoio oriundo da lei por parte de gestores; a adequação dos espaços escolares para abrigar essa população de crianças pequenas. É necessário que tal inclusão se faça realmente com primor, atendendo a seu objetivo principal, que é o de levar boa educação à maioria das crianças brasileiras, que ficam na "periferia” da escola.

Deve haver uma reformulação geral nos conteúdos do Ensino Fundamental, desde a base, que é esse primeiro ano, ancorada no segmento anterior, de modo que não ocorra defasagem - como a que foi apontada pela professora da escola particular. Quando a criança vai para o segundo ano, há uma diferença, porque o primeiro ano está sendo considerado como o antigo pré e não há um projeto claro que alinhave o que há antes do primeiro ano, tampouco o que haverá nos anos subsequentes, até o nono ano.

Acrescentou-se uma série, a inicial, e o que vem depois continuou da mesma maneira, alterando-se apenas a nomenclatura, de sorte que remanesce um vácuo no processo, o que gera desencontros. As respostas dos professores e gestores indicam dúvidas, contradições, desconhecimento de causa em vários pontos.

Em 2013, não se pode ainda afirmar que essa reforma esteja realizada de maneira satisfatória. Há um longo caminho a percorrer para se achar o "tom" desse primeiro ano do Ensino Fundamental.

Fica claro que ainda falta configurar a estrutura desse "novo" Ensino Fundamental de nove anos, em termos de objetivos delineados, grade curricular e conteúdos alinhavados, como também o que é ou será o professor desse primeiro ano. De acordo com os dados pesquisados, os que assumiram a tarefa, com toda a experiência que possuem 
com crianças de 6 anos, não estão seguros do trabalho que realizam.

\section{Sugestões de continuidade para novos estudos}

Daqui a quatro anos, todos os dados coletados para esta pesquisa farão parte de um novo contexto educacional que se vislumbra para o país, mediante a Emenda ${ }^{\circ}$ 59, de 11 de novembro de 2009, que redimensiona a educação básica para a nação, com escolaridade obrigatória dos 4 aos 17 anos.

Esse mergulho em um contexto maior exige uma emergência de estudo para o futuro próximo. Há que se realizar fóruns de debates, encontros, formação continuada de professores nas bases escolares, maior participação da sociedade nas discussões dos encaminhamentos da educação básica no país, para que não aconteça de novo o que se viu com a implantação da Lei 11.274/2006, que gerou muita dúvida, insatisfação e desconhecimento por parte da sociedade.

Mesmo não tendo sido esse o foco desta pesquisa, não se poderia deixar de considerar esse documento que já está posto e que logo fará parte não só na letra, como na forma do cotidiano escolar. Isso impele à reflexão sobre as mudanças, cujas premissas são a ampliação do Ensino Fundamental no país, garantindo-se o acesso de todos à educação básica nacional e incitando-os a pensar sobre os processos políticos de mudança.

Para além de considerar-se o Ensino Fundamental como básico, há que se rever como essas implantações estão ocorrendo, de modo a atender e garantir uma educação de qualidade no Brasil.

Como se pode, neste momento, alinhavar e costurar o ensino fundamental de 9 anos até o final de 2015, de modo que, com a chegada de 2016 e com a inserção da Emenda Constitucional n 59, o “terreno" já esteja preparado para receber as crianças de 4 anos de idade em um ensino que preveja a qualidade, a formação continuada de profissionais, as estruturas curriculares, os espaços, a compreensão e o entendimento do desenvolvimento infantil e, mais que isso, o significado de se abarcar a criança de 4 anos no sistema da educação básica?

Presume-se que as crianças de 4 e 5 anos serão incorporadas nesta grande linha vertical que é o Ensino Fundamental. Haverá que se pensar, novamente, em reconfigurações que atendam ao novo formato, sendo a Educação Infantil definitivamente incorporada ao Fundamental.

Assim como este trabalho surgiu de dúvidas e angústias quanto ao primeiro ano do Ensino Fundamental, tem-se agora a questão futura da educação básica dos 4 aos 17 anos, que não pode ser pesquisada neste momento, mas que ficará em estado de hibernação até que pesquisadores busquem suas respostas.

\section{Referências}

ARELARO, L. R. G.; JACOMINI, M. A.; KLEIN, S. B. O ensino fundamental de nove anos e o direito à educação. In: Revista Educação e Pesquisa, São Paulo, v.37, n.1, 220, p.35-51, jan./abr.2011.

BRASIL. Constituição da República Federativa do Brasil. Brasília: Senado Federal, Centro Gráfico, 1988. Promulgada em 05 de outubro de 1988.

Emenda Constitucional $n^{\circ}$. 59, de 11 de novembro de 2009. Diário Oficial da União, Brasília, DF, 12 nov. 2009.

Lei ${ }^{\circ} 4.024$ de 20 de dezembro de 1961. Fixa as Diretrizes e Bases da 
Educação Nacional. Diário Oficial, Brasília: DF, 27 dez. 1961.

Lei $\mathrm{n}^{\circ} 5.692$ de 11 de agosto de 1971. Fixa Diretrizes e Bases para o Ensino de $1^{\circ}$ e $2^{\circ}$ graus, e dá providências. Diário Oficial da União, Brasília: DF, 12 ago. 1971.

Lei $n^{0} 8.069$ de 13 de julho de 1990. Dispõe sobre o Estatuto da Criança e do Adolescente de dá outras providências. Diário Oficial da União, Brasília: DF, 16 jul. 1990.

Lei $\mathbf{n}^{\circ} 9.394$ de 20 de dezembro de 1996. Estabelece as Diretrizes e Bases da Educação Nacional. Diário Oficial da União, Brasília: DF, 23 dez. 1996.

Lei $n^{\circ} 11.114$ de 16 de maio de 2005. Altera os artigos $6^{\circ}, 30,32$ e 87 da Lei 9.394, de 20 dez. 1996, que estabelece as Diretrizes e Bases da Educação Nacional, dispondo sobre a duração de 9 (nove) anos para o ensino fundamental. Com a matrícula obrigatória aos seis (seis anos de idade). Diário Oficial da União, Brasília: DF, 17 maio 2005.

Lei $\mathrm{n}^{\circ} 11.274$ e 06 de fevereiro

de 2006. Altera a redação dos artigos 29, 30 , 32 e 87 da Lei 9.394, de 20 dez. 1996, que estabelece as Diretrizes e Bases da Educação Nacional, dispondo sobre a duração de 9 (nove) anos para o ensino fundamental. Com a matrícula obrigatória aos 6 (seis anos de idade). Diário Oficial da União, Brasília: DF, 7 fev. 2006.

Ministério da Educação. Ensino

Fundamental de Nove Anos: orientações gerais. Brasília. Jul. 2004. 26p. Disponível em: <http://portal.mec.gov.br/seb/arquivos/ pdf/Ensfund/noveanorienger.pdf.>. Acesso em: 4 ago. 2013.

Ministério da Educação. Secretaria

de Educação Básica. Ensino fundamental de nove anos: orientações para a inclusão da criança de seis anos de idade. Beauchamp, J., Pagel, S. D., Nascimento, A. R. (Orgs.). Brasília: 2007, 135 p.

CORREA, B. C. Educação Infantil e Ensino Fundamental: desafios e desencontros na implantação de uma nova política. In: Revista Educação e Pesquisa, São Paulo, v.37, n.1, 220, p.105-20. jan/abr. 2011.

CUNHA, M. I. da. Profissionalização docente: contradições e perspectivas. In: VEIGA, I. P.; CUNHA, M. I. da (Orgs.). Desmistificando a profissionalização do magistério. Campinas: Papirus, 1999, p.127-47.

DUBAR, C. A socialização: construção das identidades sociais e profissionais. São Paulo: Martins Fontes, 2005.

EVANGELISTA, O.; SHIROMA, E. O. Professor: protagonista e obstáculo da reforma. In: Educação e Pesquisa, São Paulo, v.33, n.3, p.531-41, set./dez. 2007.

FERREIRA, F. I. Reformas educativas, formação e subjectividades dos professores. In: Rev. Bras. Educ. [online]. 2008, vol. 13, $\mathrm{n}^{\circ}$ 38, p.239-51.

GATTI, B. A. A. Os professores e suas identidades: o desvelamento da heterogeneidade. Cadernos de Pesquisa, n. 98, 1996, p.8590.

GOULART, C. A organização do trabalho pedagógico: alfabetização e letramento como eixos orientadores. In: Ensino Fundamental de nove anos: orientação para inclusão da criança de seis anos de idade. Brasília: MEC, SEB, 2007, p. 85-95.

HASHIMOTO, C. Ensino Fundamental de nove anos: um novo caminho em velha estrada? Um velho caminho em nova estrada? Tese de Doutorado, PUC/SP. 2012. 250p.

Olhar de professor, Ponta Grossa, 16(1): 107-128, 2013. Disponível em <http://www.uepg.br/olhardeprofessor> 
IMBERNÓN, F. Formação docente e profissional. 6. ed. São Paulo: Cortez, 2006.

KISHIMOTO; K. M. et al. Jogo e letramento: crianças de seis anos no ensino fundamental. In: Revista Educação e Pesquisa. São Paulo, v.37, n.1, 220, p. 191-210, jan./abr. 2011.

LOURENCETTI, G. C. O processo de intensificação no trabalho docente dos professores secundários. GT: Didática/n.04 29 Reunião Anual da Anped, Caxambu, 2006 . Disponível em: <http://www.anped.org.br/ reunioes/29ra/trabalhos/trabalho/gt04-1707-int.pdf.>. Acesso em: 5 ago. 2013.

NOGUEIRA, A. L. H.; CATANANTE, I. T. Trabalho docente e desenvolvimento das atividades simbólicas: considerações para o ensino fundamental de nove anos. In: Revista Educação e Pesquisa, São Paulo, v.37, n.1, 220, p.175-90, jan./abr. 2011.

NÓVOA, A. Professores: imagens do futuro presente. Lisboa: Educa, 2009.

PANSINI, F.; MARIN, A. P. O ingresso de crianças de seis anos no ensino fundamental: uma pesquisa em Rondônia. In: Revista Educação e Pesquisa, São Paulo, v.37, n.1, 220, p.87-103, jan./abr.2011.

PLACCO, V. M. N. S.; SOUZA, V. L. T. (Orgs.). Aprendizagem do adulto professor. São Paulo: Loyola, 2006.

SHULMAN, L. S. Knowledge and Teaching: Foundations of the New Reform. In: Harvard Educational Review, v.57, $\mathrm{n}^{\circ}$ 1, p.1-22, 1987.(inclui tradução livre) Conhecimento e ensino: bases de uma reforma. p 1-28.

TARDIF, M. Saberes docentes e formação profissional. Petrópolis: Vozes, 2012.

Enviado em: 30/05/2013

Aceito em: 26/06/2013 